УДК 666.948: 666.972.112

DOI https://doi.org/10.32838/2663-5941/2020.4/27

Шишкин А. А.

Криворожский национальный университет

\title{
ИССЛЕДОВАНИЕ ВЛИЯНИЯ МИЦЕЛЛООБРАЗУЮЩИХ ПОВЕРХНОСТНО-АКТИВНЫХ ВЕЩЕСТВ И ИХ СМЕСЕЙ НА ПРОЧНОСТЬ РЕАКЦИОННОГО ПОРОШКОВОГО БЕТОНА
}

За певних умов збільшення швидкості гідратації в'яжучої речовини сприяє збільшенню міцності бетону при стиску. Це стосується і реактивних порошкових бетонів. Дослідження, спрямовані на подальще вдосконалення і розробку технологї бетону на основі портландиементу з використанням вищезазначених поверхнево-активних речовин, актуальні. Використання сполук двох або кількох поверхнево-активних речовин може дати змогу змінити або розширити якісні показники або властивості реакиійного порошкового бетону. Вивчено вплив різного виду поверхнево-активних речовин, здатних утворювати міџели, $i$ їх сумішей на швидкість утворення $і$ кінцеве значення міџності на стиск портландиементних порошкових бетонів. Особливістю дослідження було вивчення одночасного впливу суміші поверхнево-активних речовин, які утворюють мічели, які відрізняються своєю взаємодією з водою, зокрема олеата натрію і стеарата кальцію, на зміну міцності бетону. Встановлено, щчо міцелярні розчини зазначених речовин змінюють характер формування міцності портландиементних реактивних порошкових бетонів. Швидкість формування міџності в початкові періоди збільшується завдяки міцелярному каталізу гідратаџії портландиементу, а їх підвищена міџність на стиск зберігається на більи пізніх стадіях зміинення. Міџність портландиементних реактивних порошкових бетонів із використанням суміші поверхнево-активних речовин, здатних утворювати міцели, сягає 190\% міцності таких бетонів без добавок. Було доведено, що міщелярний каталіз можна використовувати для керування проиесом твердіння сумімі портландиементу з водою, що призводить до підвищення міцності отриманого штучного каменю. За рахунок изого скорочується час досягнення розрахункової міиності бетону, а абсолютна величина міцності на стиск таких бетонів у віці 28 днів збільшується.

Ключові слова: портландцемент, олеат натрію, стеарат кальиію, міцелярний каталіз, міцність бетону, порочковий бетон, мічели, поверхнево-активні речовини.

Постановка проблемы. С каждым годом увеличиваются объемы строительства с применением монолитного бетона, к которому предъявляют много требований, основной из которых является высокая скорость формирования прочности, а также в зависимости от вида и условий эксплуатации - высокий предел прочности. Основным видом вяжущих веществ, применяемых в технологии монолитного строительства, является портландцемент. Современные научные труды в области бетоноведення базируются на применении суперпластифицированных портландцементов и смесей портландцементов с различными реакционно-активными порошками, в результате чего получают так называемые реакционные порошковые бетоны (RPC), обладающие высокой прочностью при сжатии.

Анализ последних исследований и публикаций. В качестве порошков, используемых для производства реакционно-порошковых бетонов, обычно применяют микрокремнезем, метакаолин, золу унос ТЭС, горные породы. В резуль- тате применения реакционно-активных порошков и супер- или гиперпластификаторов удалось получить бетоны с прочностью при сжатии от 100 до 200 МПа и прочностью при растяжении 25-50 МПа [1;2].

Следует отметить, что такие бетоны разработаны и исследованы при использовании в качестве основного вяжущего вещества портландцемента. В то же время существует большая группа вяжущих веществ, которые не содержат минералов, аналогичных минералам портландцемента. Основой таких вяжущих веществ является тонкомолотый гранулированный доменный шлак, который смешивают с водным раствором щелочного компонента (шлакощелочные бетоны) [3]. В состав таких бетонов рекомендуется [4] вводить реакционно-активные порошки, в частности содержащие ионы переходных химических элементов. Указанные бетоны имеют другую природу и механизм гидратации, чем цементы, а прочность таких бетонов достигает 100 МПа при скорости твердения, превышающей скорость твердения дисперсных 
систем на основе портландцементов. Однако данные бетоны обладают повышенной деформативностью, что сдерживает их применение. Современное состояние развития строительства требует дальнейшего улучшения свойств бетонов на основе традиционных вяжущих веществ, в том числе и портландцемента, путем модификации их структуры.

Установлено, что повышение прочности бетона происходит при одновременном введении в его состав минерального комплекса, содержащего железо и полиспирты [5].

Использование сочетаний двух или нескольких поверхностно-активных веществ (далее ПАВ) может дать возможность изменить или расширить качественные показатели или свойства реакционного порошкового бетона. Неадитивное изменение того или иного показателя часто относят за счет синергизма или, наоборот, антагонизма между молекулами ПАВ. Примером синергизма, обусловленного наличием взаимодействия, может служить система «коллоидное поверхностно-активное вещество - высший спирт - вода». Добавки высших жирных спиртов снижают критическую концентрацию мицеллообразования (ККМ) коллоидного поверхностноактивного вещества, поверхностное натяжение, повышают вязкость адсорбционных слоев коллоидного поверхностно-активного вещества и, как следствие, увеличивают стабильность дисперсий. Причиной этого служит образования водородной связи между гидроксилом спирта и карбоксильной группой коллоидной поверхностно-активного вещества.

Исследования показывают, что при добавлении определенных количеств спирта к воде наблюдается стабилизация раствора, которая определяется в основном ассоциацией частиц, а также переходом менее упорядоченных структур в более упорядоченные. Так как жидкая вода состоит из областей определенного строения, называемых кластерами, при добавлении спирта сначала заполняются пустоты между кластерами, что приводит к их стабилизации, а затем молекулы спирта начинают конкурировать за водородные связи внутри кластеров. При этом гидрофильные группы спиртов могут замещать молекулы воды в локальных образованиях. Особенно легко в структуру воды внедряются небольшие по размеру молекулы спирта, которые, попадая в локальные молекулярные образования, сохраняют пространственное расположение молекул воды. Это подтверждает тот факт, что при добавлении спирта к воде наблюдается уменьше- ние межслойных расстояний по сравнению с теми же значениями для воды. С ростом алкильного радикала происходит постепенное увеличение межслойных расстояний, что доказывает разрушительное воздействие более объемных молекул спирта, которое сопровождается существенными перестройками пространственного расположения молекул в локальных образованиях воды.

Спирты упорядочивают водную структуру, что облегчает перемещение протонов и ионов гидроксила по сетке водородных связей (эстафетный механизм электропроводности). В присутствии спирта, через гидрофобные взаимодействия, вода уже частично структурирована.

Введение в систему «портландцемент - вода» полиспиртов (например, глицерина или этиленгликоля) в начальные сроки гидратации практически не меняет кинетику растворения силикатов и мало отражается на составе жидкой фазы. Но в дальнейшем происходит поглощение полиспиртами ионов $\mathrm{Ca}^{2+}$ из жидкой фазы с образованием глицератов кальция. То есть полиспирты в рассматриваемой системе в более поздние сроки выполняют роль пуццолановый добавки.

Благодаря экранирующему действию недиссоциированных полярных групп спирта уменьшаются силы электрического отталкивания между одноименно заряженными полярными группами ПАВ, т. е. уменьшается количество МПАВ в системе при сохранении величины эффекта их присутствия.

Автором с сотрудниками получены реакционные порошковые бетоны, содержащие в качестве коллоидных поверхностно-активных веществ олеат натрия или его смесь с полиспиртом [6; 7]. Повышение качества бетона в данном случае происходит из-за повышенной степени структурирования воды наночастицами - димерами коллоидных поверхностно-активных веществ и молекулами полиспирта.

Однако полиспирты не являются отходом производства, поэтому имеют достаточно высокую стоимость, что ограничивает их применение.

Попытки повысить прочность бетона заменой олеата натрия на стеарат кальция [8; 9] не привели к успеху.

В тоже время вопрос совместного использования нескольких видов ПАВ, в том числе и коллоидных, до настоящего времени не рассмотрен достаточно в научной литературе, а такое их использование может привести к достаточно эффективным решениям, способствующим дальнейшему увеличению прочности бетона. 
Постановка задания. Целью работы является определение влияния смеси мицеллообразующих ПАВ (МПАВ) на скорость формирования прочности реакционного порошкового бетона и ее величину. Для достижения цели были поставлены следующие задачи: определить влияние поверхностно-активных веществ, образующих мицеллы, на величину прочности при сжатии реакционного порошкового бетона; определить влияние поверхностно-активных веществ, образующих мицеллы, на скорость формирования прочности при сжатии реакционного порошкового бетона.

Изложение основного материала исследований. Для изготовления бетона использовали стандартный портландцемент М400 производства ПрАО «Хайдельберг цемент» (г. Кривой Рог, Украина), в качестве мелкого заполнителя отходы обогащения железных руд Южного горнообогатительного комбината (г. Кривой Рог, Украина), которые имеют размер частиц от 0,001 до 0,63 мм. В качестве поверхностно-активных веществ, образующих мицеллы (МПАВ), применяли олеат натрия (Simagchem Corp., Китай) и стеарат кальция (M.L.A. Индия). Олеат натрия и стеарат кальция растворяли в воде до требуемой, согласно плану эксперимента, концентрации. Водный раствор олеата натрия, смеси олеата натрия и стеарата кальция или смеси олеата натрия и глицерина в количестве, рассчитанном по плану эксперимента, добавляли в емкость с отдозированным количеством воды. Изготовление и испытания образцов бетона осуществляли по стандартным методикам.

В процессе выполненных экспериментов установлено, что прочность цементного камня без добавок составила: в возрасте 3 суток - 12,7 МПа, 7 дней - 27,1 МПа, 28 дней - 43,3 МПа. Эти величины прочности приняты за $100 \%$ для определенного возраста бетона. Проведенные исследования показали (табл. 1-3), что применение смеси коллоидных МПАВ для получения бетона приводит к увеличению прочности последнего в любом возрасте его твердения в рамках эксперимента (от 3 до 28 суток).

Кинетика изменения прочности исследуемого бетона в зависимости от вида и содержания поверхностно-активных веществ определялась на протяжении 90 суток (рис. 1).

Через 28 суток твердения бетона на основе бездобавочного портландцемента составляет 43,3 МПа, в то время как прочность бетона, модифицированного структурированной олеатом натрия водой, достигает 52 МПа, а структурированной смесью олеата натрия и стеарата кальция
Таблица 1

Влияние смеси ПАВ на прочность при сжатии RPC в возрасте 3 суток

\begin{tabular}{|c|c|c|c|c|c|}
\hline \multicolumn{2}{|c|}{ Дополнительное ПАВ } & \multirow{2}{*}{\multicolumn{4}{|c|}{$\begin{array}{l}\text { Относительная прочность } \\
\text { бетона, \%, при концентра- } \\
\text { ции раствора олеата натрия }\end{array}$}} \\
\hline \multirow{2}{*}{ вид } & \multirow{2}{*}{$\begin{array}{c}\text { содержа- } \\
\text { ние, \% }\end{array}$} & & & & \\
\hline & & 0 & $10^{-3} \mathrm{M}$ & $10^{-4} \mathrm{M}$ & $10^{-5} \mathrm{M}$ \\
\hline- & - & 100 & 165 & 176 & 170 \\
\hline глицерин & 0,1 & 102 & 134 & 144 & 136 \\
\hline глицерин & 0,2 & 105 & 143 & 153 & 142 \\
\hline глицерин & 0,3 & 107 & 140 & 147 & 136 \\
\hline $\begin{array}{l}\text { стеарат } \\
\text { кальция }\end{array}$ & $10^{-3} \mathrm{M}$ & 105 & 170 & 190 & 186 \\
\hline $\begin{array}{l}\text { стеарат } \\
\text { кальция }\end{array}$ & $10^{-4} \mathrm{M}$ & 110 & 199 & 202 & 198 \\
\hline $\begin{array}{l}\text { стеарат } \\
\text { кальция }\end{array}$ & $10^{-5} \mathrm{M}$ & 115 & 188 & 198 & 186 \\
\hline
\end{tabular}

Таблица 2

Влияние смеси ПАВ на прочность при сжатии RPC в возрасте 7 суток

\begin{tabular}{|c|c|c|c|c|c|}
\hline \multicolumn{2}{|c|}{ Дополнительное ПАВ } & \multirow{2}{*}{\multicolumn{4}{|c|}{$\begin{array}{c}\text { Относительная прочность } \\
\text { бетона, \%, при концентрации } \\
\text { раствора олеата натрия }\end{array}$}} \\
\hline \multirow{2}{*}{ вид } & \multirow{2}{*}{$\begin{array}{c}\text { содержа- } \\
\text { ние, \% }\end{array}$} & & & & \\
\hline & & 0 & $10^{-3} \mathrm{M}$ & $10^{-4} \mathrm{M}$ & $10^{-5} \mathrm{M}$ \\
\hline- & - & 100 & 168 & 179 & 174 \\
\hline глицерин & 0,1 & 106 & 144 & 164 & 156 \\
\hline глицерин & 0,2 & 115 & 153 & 173 & 162 \\
\hline глицерин & 0,3 & 121 & 160 & 157 & 146 \\
\hline $\begin{array}{l}\text { стеарат } \\
\text { кальция }\end{array}$ & $10^{-3} \mathrm{M}$ & 108 & 178 & 199 & 196 \\
\hline $\begin{array}{l}\text { стеарат } \\
\text { кальция }\end{array}$ & $10^{-4} \mathrm{M}$ & 112 & 204 & 209 & 205 \\
\hline $\begin{array}{l}\text { стеарат } \\
\text { кальция }\end{array}$ & $10^{-5} \mathrm{M}$ & 118 & 193 & 198 & 186 \\
\hline
\end{tabular}

Таблица 3

Влияние смеси ПАВ на прочность при сжатии RPC в возрасте 28 суток

\begin{tabular}{|c|c|c|c|c|c|}
\hline \multicolumn{2}{|c|}{ Дополнительное ПАВ } & \multirow{2}{*}{\multicolumn{4}{|c|}{$\begin{array}{c}\text { Относительная прочность } \\
\text { бетона, \%, при концентрации } \\
\text { раствора олеата натрия }\end{array}$}} \\
\hline \multirow{2}{*}{ вид } & \multirow{2}{*}{$\begin{array}{c}\text { содержа- } \\
\text { ние, \% }\end{array}$} & & & & \\
\hline & & 0 & $10^{-3} \mathrm{M}$ & $10^{-4} \mathrm{M}$ & $10^{-5} \mathrm{M}$ \\
\hline- & - & 100 & 125 & 126 & 120 \\
\hline глицерин & 0,1 & 102 & 128 & 128 & 126 \\
\hline глицерин & 0,2 & 105 & 133 & 133 & 132 \\
\hline глицерин & 0,3 & 107 & 130 & 127 & 126 \\
\hline $\begin{array}{l}\text { стеарат } \\
\text { кальция }\end{array}$ & $10^{-3} \mathrm{M}$ & 109 & 140 & 145 & 146 \\
\hline $\begin{array}{l}\text { стеарат } \\
\text { кальция }\end{array}$ & $10^{-4} \mathrm{M}$ & 113 & 149 & 153 & 168 \\
\hline $\begin{array}{l}\text { стеарат } \\
\text { кальция }\end{array}$ & $10^{-5} \mathrm{M}$ & 118 & 148 & 148 & 156 \\
\hline
\end{tabular}




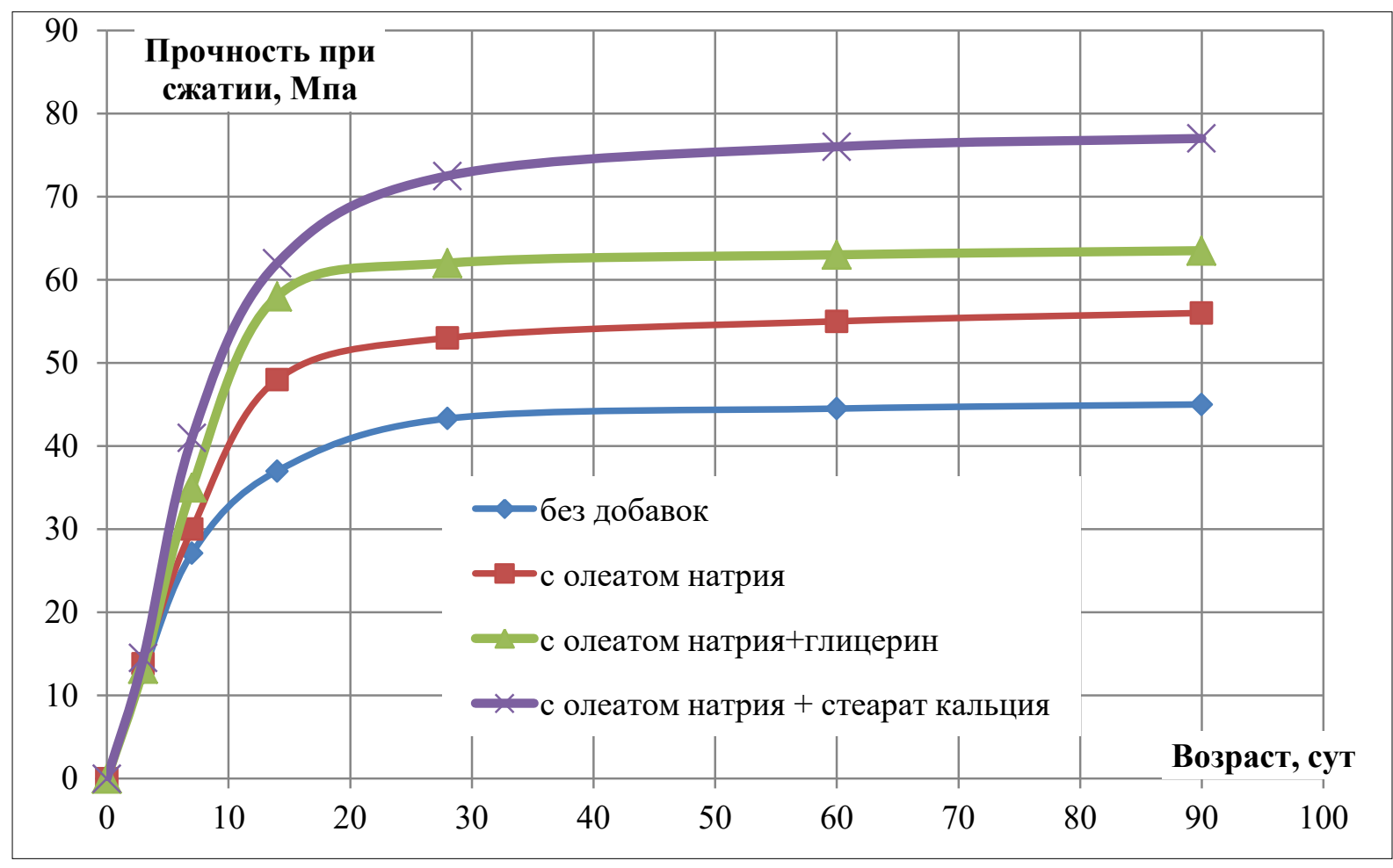

Рис. 1. Изменение прочности бетона во времени (концентрация растворов коллоидных поверхностно-активных веществ составляет $10^{-5} \mathrm{M}$, содержание глицерина - 0,2\%)

превышает 72 МПа. Через 3 суток твердения показатель удельной прочности наномодифицированного цементного камня $\left(f_{\text {ck.cube3 }} / f_{\text {ck.cube28 } 8}\right)$ составляет 0,78 , а через 7 суток $\left(f_{\text {ck.cube }} / f_{\text {ck.cube28 } 8}\right)-0,95$.

Так, до трех суток дисперсные системы набирают прочность со скоростью:

- контрольная (бездобавочная) - 4,2 МПа/сут;

- содержащая олеат натрия - 4,6 МПа/сут.;

- содержащая смесь олеата натрия и глицерина - 4,4 МПа / сут.;

- содержащая смесь олеата натрия и стеарата кальция - 4,8 МПа/сут.

Результаты проведенных исследований показали, что определенные гидрофобные ПАВ (в частности, олеат натрия) обеспечивают увеличение прочности цементного камня. Это может быть объяснено тем, что олеат натрия относится к коллоидным ПАВ (МПАВ) и имеет линейную структуру углеводородного радикала.

Другие использованные ПАВ, которые имеют линейную структуру углеводородного радикала (стеарат кальция и глицерин), также обеспечивают значительное увеличение прочности цементного камня, но меньше, чем олеат натрия. Это явление можно объяснить различием в длине углеводородного радикала примененных МПАВ.

В возрасте 28 суток значительно уменьшается влияние МПАВ на прочность цементного камня. То есть к этому времени реакции гидратации практически заканчиваются, как у обычного цемента, так и у цемента, который твердеет с водой, структурированной МПАВ. Очевидно, прочность цементного камня, который создан в результате затвердевания дисперсной системы «портландцемент - димеры МПАР - вода», «показывает» прочность, которую может приобрести цементный камень без добавок в больший срок твердения.

На основании выполненных исследований определена однозначно тенденция повышения прочности при твердении дисперсной системы «портландцемент - вода - димеры МПАВ».

Как было показано выше, наиболее существенный эффект модификации цементного камня димерами МПАВ наблюдается при концентрации последних в воде затворения в достаточно узком интервале.

Результаты опытов показали, добавление в реакционный порошковый бетон мицеллообразующих ПАВ или их смесей приводит к увеличению прочности бетона. В общем случае концентрация водного раствора МПАВ или смеси МПАВ в реакционном порошковом бетоне, которая обеспечивает получение максимальной прочности бетона при сжатии, составляет от $10^{-4} \mathrm{M}$ до $10^{-5} \mathrm{M}$. Изменение прочности бетона во времени 
увеличивается при введении МПАВ. Преимуществом результатов проведенных исследований является определенная возможность значительного (до 200\%) увеличения прочности порошкового бетона на основе портландцемента. Однако существуют и определенные ограничения в применении результатов этого исследования. Так, необходимо контролировать сроки схватывания бетона, которые при применении определенных видов щелочного компонента могут быть довольно малыми. В дальнейшем для расширения области применения исследованных бетонов целесообразно изучить влияние мицеллярного катализа на деформативные свойства.

Выводы. Введение в состав реакционного порошкового бетона МПАВ или их смесей обеспечивает повышение прочности бетона на сжатие, которая достигает $160 \%$ от прочности бетона аналогичного состава, полученного без применения МПАВ.

\section{Список литературы:}

1. Фаликман В.Р. Новые эффективные высокофункциональные бетоны. Бетон и железобетон. 2011. № 2. C. $78-84$.

2. Erdem, T.K., Kirca O. Use of binary and ternary blends in high strength concrete. Construction and Building Materials. 2008. 22, 7. P. 1477-1483. DOI: 10.1016/j.conbuildmat.2007.03.026.

3. КривенкоП.В.Роль технологических факторов в формировании структуры и свойств шлакощелочных бетонов. Вісник ОДАБА. 2015. № 57. С. 38-45.

4. Шишкин А.А. Щелочные реакционные порошковые бетоны. Строительство уникальных зданий и сооружений. 2014. № 2(17). С. 56-65.

5. Shishkin A., Shishkina A., Vatin N. Low-shrinkage alcohol cement concrete. Applied Mechanics and Materials. 2014. 633-634. P. 917-921. doi: 10.4028/www.scientific.net/amm.633-634.917.

6. Shishkina A., Shishkin A. Research into effect of complex nanomodifiers on the strength of fine-grained concrete. Eastern-European Journal of Enterprise Technologies. 2018. 2/6 (92). P. 29-33.

7. Шишкина А.А., Шишкин А.А. Влияние коллоидных поверхностно-активных веществ на прочность мелкозернистых бетонов. Наука та будівництво. 2016. № 1(7). С. 10-13.

8. Калашников В.И., Махамбетова К.Н., Шитова И.Ю., Самошина Е.Н., Петухов А.В. Гигрометрические свойства цементно-песчаных растворов, модифицированных современными гидрофобизаторами. Современные проблемы науки и образования. 2015. № 1-1. URL: http://www.science-education.ru/ru/article/ view?id=18783 (дата обращения: 07.07.2020).

9. Калашников В.И., Махамбетова К.Н., Троянов И.Ю., Петровский Д.А. Исследование влияния катиона металла стеаратов и дозировки их на водопоглощение и прочность модифицированного цементного композита. Строительные материаль, оборудование, технологии ХХІ века. 2009. № 12. С. 14-15. URL: https://rucont.ru/efd/412658 (дата обращения: 07.07.2020).

\section{Shyshkin A.A. RESEARCH OF THE INFLUENCE OF MICELLO-FORMING SURFACE-ACTIVE SUBSTANCES AND THEIR MIXTURES ON THE STRENGTH OF REACTIVE POWDER CONCRETE}

Under certain conditions, an increase in the speed of binder hydration helps to increase the compressive strength of concrete. This is especially true for reactive powder concrete. Considering the specific influence of the surfactants that form micelles, research is relevant to further improve and develop concrete technology based on Portland cement using the aforementioned surfactants. The effect of various types of surfactants capable of forming micelles and their mixtures on the rate of formation and the final value of the compressive strength of Portland cement powder concretes was studied. A feature of the study was the study of the simultaneous effect of a mixture of surfactants that form micelles, which differ in their interaction with water, in particular sodium oleate and calcium stearate, on the change in concrete strength. It was found that these micellar solutions change the nature of the strength formation of Portland cement reactive powder concrete. The rate of formation of strength in the initial periods increases due to micellar catalysis of hydration of Portland cement, and their increased compressive strength remains at later stages of hardening. The strength of Portland cement reactive powder concrete using a mixture of surfactants capable of forming micelles, reaches $190 \%$ of the strength of such concrete without additives. It has been proven that micellar catalysis can be used to control the curing process of a mixture of Portland cement and water, and to give strength to the resulting artificial stone. Due to this, the time to reach the estimated concrete strength is reduced, and the absolute value of the compressive strength of such concrete at the age of 28 days is increased.

Key words: Portland cement, sodium oleate, calcium stearate, micellar catalysis, concrete strength, powder concrete, micelles, surfactants. 